\title{
Evaluating a clinical practice intervention to promote delivery of salbutamol by metered-dose inhalers with holding chambers in a pediatric emergency department
}

\author{
Barbara J. Hill-Taylor, BSP, BFA, MLIS*; Katrina F. Hurley, MD, MHI ${ }^{\dagger}$; Ingrid Sketris, PharmD, MPA \\ (HSA)*; Colleen O'Connell, $\mathrm{PhD}^{\ddagger}$; Douglas Sinclair, $\mathrm{MD}^{\S}$; Andrew Wing, BSc ${ }^{\|}$
}

\section{ABSTRACT}

Objective: The primary objective of this study was to quantify the impact of a clinical practice intervention to promote the delivery of salbutamol by metered-dose inhaler (MDI) in a pediatric emergency department (PED). A secondary objective was to retrospectively document the components of the intervention.

Methods: PED inventory data for salbutamol inhalation solution (nebules), MDIs, and holding chambers were obtained from the pharmacy department. Patient data were obtained from the hospital's decision support unit. Interrupted time series analysis was used to evaluate trends in salbutamol inventory data, patient triage acuity, and hospital admissions from January 1, 2003, to May 31, 2010. Interviews and administrative documents were used to identify components of the intervention, which began in 2006.

Results: There was a $1,215 \%$ increase in the proportion of salbutamol delivered as MDIs compared to total inhaled salbutamol (MDI plus nebulization solution) following the intervention ( $95 \% \mathrm{Cl} 1,032 \%$ to $1,396 \%, p<0.001$ ). Increases in salbutamol MDI use were associated with the implementation of an institution-specific asthma care map. A relative decrease of $32 \%$ in the hospital admission rate (absolute $-7.25 \%$ : $95 \% \mathrm{Cl}-8.31$ to $-6.19, p<0.001$ ) was associated with the change in salbutamol MDI use and the use of the asthma care map.

Conclusions: A multifaceted intervention, designed and implemented by local PED clinical leaders, resulted in a pronounced change in salbutamol inhalation practice, with an associated decrease in admission rates. This intervention demonstrated many of the criteria for successful health system change. Findings from this research may be contextualized to inform change elsewhere.

\section{RÉSUMÉ}

Objectif: L'étude avait pour objectif principal de quantifier l'incidence d'une intervention clinique visant à promouvoir I'administration de salbutamol au moyen d'un aérosoldoseur (AD) dans un service d'urgences pédiatriques (SUP) hautement spécialisé.

Méthode: Les données sur le nombre de nébules de salbutamol en solution pour inhalation, d'AD, et de chambres d'inhalation au SUP ont été obtenues du service de pharmacie. Les données sur les patients, elles, ont été obtenues du service d'aide à la décision de l'hôpital. Nous avons eu recours à l'analyse de séries temporelles interrompues pour évaluer les tendances observées dans les données sur la quantité de salbutamol, la gravité de l'état des patients au moment du triage, et les hospitalisations, du 1er janvier 2003 au 31 mai 2010. Des entrevues et des documents administratifs ont servi à la détermination des composants de l'intervention, qui a commencé en 2006.

Résultats: Une augmentation de 1,215\% de la proportion de salbutamol administré au moyen d'un AD comparativement à la quantité totale de salbutamol administré en inhalation (AD plus solution pour nébulisation) a été relevée à la suite de I'intervention (IC à $95 \% 1,032 \%$ à 1,396 \%; $p<0.001$ ). L'augmentation de I'utilisation du salbutamol en AD a été associée à la mise en œuvre d'un plan de soins relatif à I'asthme et propre à l'établissement. Une réduction relative de $32 \%$ du taux d'hospitalisation (réduction absolue: 7.25; IC à $95 \%$ : -8.31 à $-6.19, p<0.001$ ) a également été associée au changement d'utilisation du salbutamol en $A D$ et à I'application du plan de soins relatif à l'asthme.

Conclusions: Une intervention à facettes, conçue et mise en œuvre par des chefs cliniques locaux au SUP, s'est traduite par un changement marqué de la pratique de l'administration

From *IMPART, College of Pharmacy, Dalhousie University, Halifax, NS; tEmergency Department, IWK Health Centre, Halifax, NS; ‡IWK Health Centre, Halifax, NS; §St. Michael's Hospital, Toronto, ON; ॥Dalhousie Medical School, Dalhousie University, Halifax, NS.

Correspondence to: Ms. Barbara J. Hill-Taylor, IMPART, College of Pharmacy, 1459 Oxford Street, Halifax, NS B3H 4R2; Barbara.Hill-Taylor@dal.ca. This article has been peer reviewed. 
du salbutamol en inhalation et par une diminution associée du taux d'hospitalisation. L'intervention a fait ressortir bon nombre des critères de réussite de changements apportés au système de santé. Peut-être serait-il possible d'adapter les conclusions de la recherche à d'autres contextes afin de susciter des changements ailleurs.
Keywords: asthma therapy, clinical intervention, health service research, pediatric emergency department, salbutamol inhalation
Twenty-five years of research involving acute care pediatric patients with wheeze-related illnesses has shown that $\beta$-adrenergic agonists by a metered-dose inhaler (MDI) with a holding chamber is equally as efficacious as nebulization for most patients. ${ }^{1-10}$ As early as 1997 , a review of 10 randomized, controlled trials involving 575 pediatric patients recommended that MDIs with holding chambers be considered the preferred mode of treatment in children with acute asthma. ${ }^{1}$ A Cochrane review of 27 trials involving 2,295 children supported these findings, adding that the use of MDIs with holding chambers was associated with reduced tachycardia. ${ }^{3}$ The use of MDIs with holding chambers offers several advantages, including potential cost efficiencies and improved patient health care experience (Table 1). Yet surveys of pediatric acute care settings in various Western countries continue to show that nebulization remains the dominant method for $\beta$-agonist inhalation administration, ${ }^{11-16}$ despite convincing evidence and recommendations in national and international asthma care guidelines..$^{14,17-19}$

In 2006, a qualitative study at our study site identified perceived barriers to changing the method of salbutamol inhalation delivery. ${ }^{20}$ Equipped with this knowledge, an interprofessional team of emergency department clinical leaders prepared for and implemented an intervention plan that promoted the use of salbutamol MDIs with holding chambers. The multifaceted intervention took over 2 years, beginning with discussions by the pediatric emergency department (PED) quality and operations committee. Input from inpatient clinicians and logistical negotiations with other hospital departments (pharmacy, materials, and records management) followed. Education forums and informal teaching sessions for front-line workers, as well as focus groups with medical, nursing, and support staff, took place in the latter part of 2007. Discussions with patients and caregivers, as well as public service announcements, facilitated community awareness and involvement of the clinical practice change.

The emergency department asthma care map was developed in-house through a process that involved an environmental scan of other jurisdictions, followed by local customization of existing care maps. The asthma care map was established through informal consensus and was not validated by this study. The trial of the map began in January 2008, and during the trial period, further interprofessional staff input shaped the map. It was adopted as standard practice, becoming part of patients' medical records in July 2009.

The objective of this study was to quantify the impact of this clinical practice intervention to promote the delivery of salbutamol by MDI in a tertiary care PED. The secondary objective was to retrospectively document the components of the intervention and their timing.

Table 1. Benefits of salbutamol administration via metered-dose inhalers with holding chambers versus nebulization

Patients and families Emergency department Health care system

Reduced side effects ${ }^{1,3,4,7,9} \quad$ Quieter

Reduced morbidity 5,6

Reduced administration time $e^{1,3,4,6,10}$

Reduced time and risk in maintenance of the nebulizer system in the community setting ${ }^{6,10}$

Better acceptance by patient and family?.11

Portable $^{10}$

Usually easier to administer ${ }^{6}$
Reduced cost for medication and medical devices $3,6,7,10,36$

Reduced risk of cross-infection ${ }^{11,37}$ Reduced time in department ${ }^{3,4}$

Valuable opportunity for teaching and reinforcement $t^{3,6,11}$

Reduced staffing costs ${ }^{12,36}$

Reduced morbidity/potentially reduced admissions ${ }^{6,7}$

Increased staff satisfaction

Potential to use homemade or plastic water bottle as spacer ${ }^{15}$

Electricity/compressed air not needed ${ }^{* 2,24}$

*Especially beneficial in developing countries or disaster situations. 


\section{METHODS}

\section{Study design}

This was a retrospective study employing an interrupted time series design to evaluate the changes in inhaled salbutamol delivery in a PED between January 1, 2003, and May 31, 2010, before and following a clinical practice intervention. Nonequivalent dependent variables (inhaled salbutamol formulation and holding chamber inventory data) were used to document the extent of the practice change. Hospital admission rates and Canadian Paediatric Triage and Acuity Scale (PaedCTAS) codes were used as a proxy for severity of illness.

Two structured interviews with a senior clinician and a nurse were conducted in August 2010 (questionnaire available on request), and the content of the interviews was used with administrative records from departmental quality and operations committee meetings to retrospectively determine specific intervention components and their timing. Ethics approval was obtained from the Research Ethics Board, IWK Health Centre, Halifax, Nova Scotia.

\section{Setting}

The IWK Health Centre is the tertiary care pediatric facility for the maritime provinces. The IWK Health Centre PED sees approximately 28,600 patients per year, ${ }^{21}$ of whom approximately 2,000 present with acute wheeze-related illness.

Before the clinical practice intervention, salbutamol delivery by MDI was rarely used in the PED. Of the patients prescribed salbutamol in the 2 years prior to the change in practice (2006-2008), 98.5\% of patients received salbutamol by nebulization (unpublished administrative data, 2010).

\section{Outcome measures}

The quantities of inhaled salbutamol formulation (MDIs, nebules: $1.25 \mathrm{mg} / 2.5 \mathrm{~mL}, 2.5 \mathrm{mg} / 2.5 \mathrm{~mL}$, $5 \mathrm{mg} / 2.5 \mathrm{~mL}$, and salbutamol inhalation solution $5 \mathrm{mg} / \mathrm{mL} \times 100 \mathrm{~mL}$ ) and the number of holding chambers supplied to the PED were the main outcome measures. Four types of Aerochamber Max holding chambers (Trudell Medical International, London, ON) were supplied over the study period, including infant, child, and adult holding chambers with attached masks and adult holding chambers without masks.
Secondary outcome measures included the numbers of patients with wheeze-related illnesses visiting the emergency department, their acuity as determined (proxy) by triage levels, and disposition.

\section{Data collection}

Inventory data for salbutamol inhalation solution (nebules), MDIs, and holding chambers (i.e., numbers supplied to the PED) were obtained from the pharmacy department. Inventory data from 2003 to 2006 were obtained from weekly ward stock filling records. In 2006, an automatic dispensing device (Pyxis Medstation, CareFusion, San Diego, CA) was installed in the PED, which generated the inventory data used for the remaining study period.

Each MDI was counted as one asthma care map equivalent. Each nebule was counted as one-third of an asthma care map equivalent in accordance with the asthma care map (i.e., three nebules or one MDI normally was required for one course of treatment).

The hospital decision support unit, which collects information as part of the National Ambulatory Care Reporting System (NACRS), supplied patient numbers, triage level, and admission rates. ${ }^{22}$ All patients coded with asthma (J45), bronchiolitis (J21), other specified respiratory disorders including reactive airway disease (J98.8), and wheeze (R06.2) based on the International Classification of Diseases and Related Health Problems, 10th revision (ICD-10), codes were included..$^{23}$

\section{Primary data analysis}

Segmented regression analysis was used to determine level and trend in the dependent measures during the postintervention phase relative to the levels and trends in the preintervention stage. The week beginning January 20, 2008, was chosen as the intervention point based on information from the interviews and administrative data. This date marked the end of the educational sessions and focus groups and the start of the trial of the institutionspecific asthma care map (available on request).

Patients were divided into two groups based on their triage level (moderate to severe patients coded PaedCTAS 1-3 and mild patients coded 4-5). Number of visits, triage, and disposition data were examined for change over the study period. Analysis was conducted using SPSS Statistics 18 (IBM SPSS, New York, NY). 


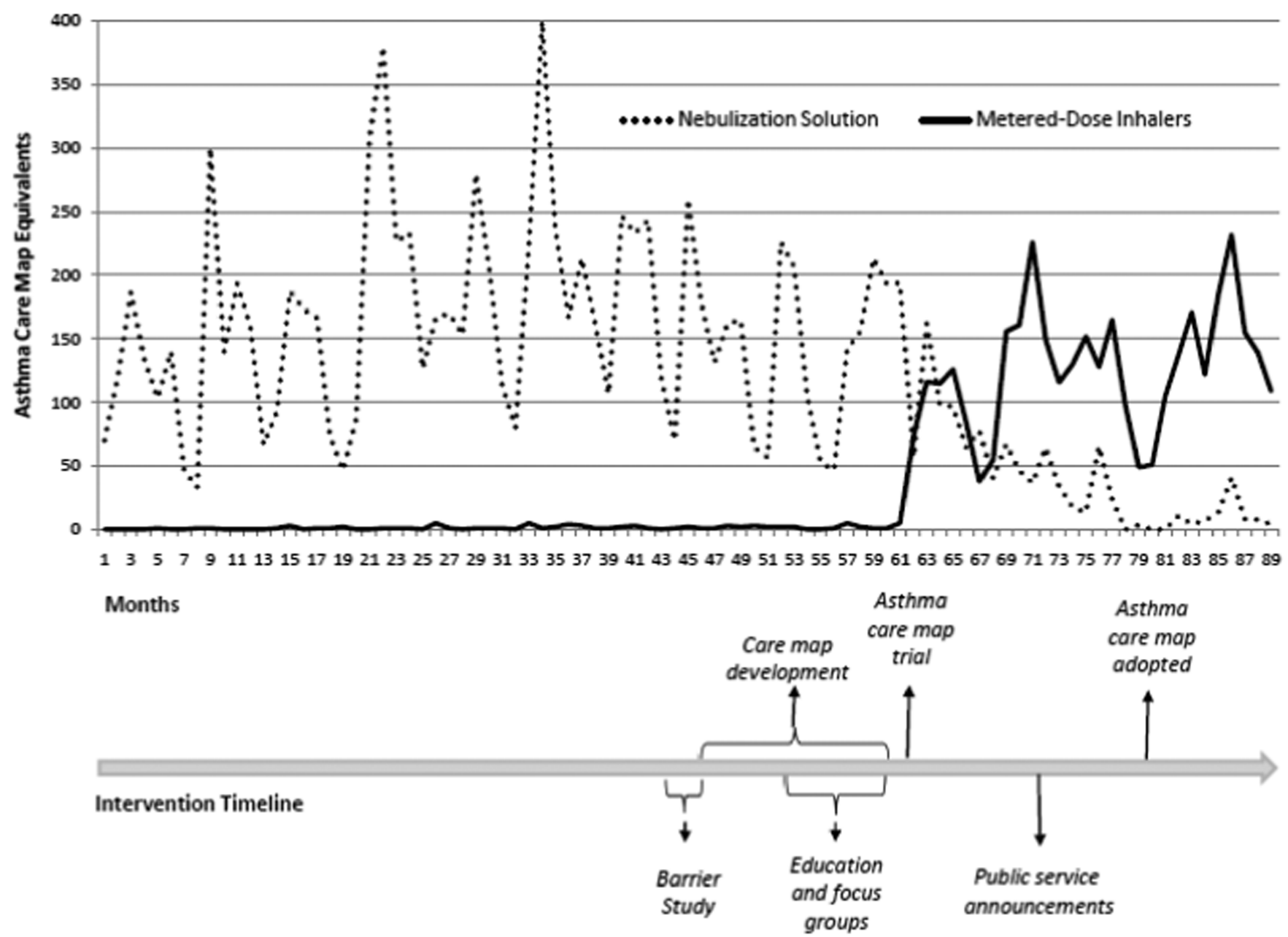

Figure 1. Asthma care map equivalents of salbutamol nebulization solution and metered-dose inhalers delivered to the pediatric emergency department from January 1, 2003, to May 31, 2010 (with intervention timeline).

\section{RESULTS}

In January 2008, the increase in MDI use was abrupt and persistent (Figure 1). Salbutamol delivery by nebulization fell less abruptly but steadily. In the 5 years prior to this date, a mean of $0.28 \mathrm{MDIs}$ were supplied to the PED per week. Following January 2008, this increased to 9.26 per week, a difference of 8.98 per week (95\% CI 7.64 to $10.31, p<0.001)$. Similarly, the mean number of holding chambers supplied to the PED increased from 0.14 to 1.8 chambers per week $(p<$ 0.0001 ), a change of $1,222 \%$ ( $95 \% \mathrm{Cl} 1,042$ to 1,402 ).

Figure 2 shows the change in the proportion of MDI to total inhaled salbutamol (MDI plus nebulization solution) over the study period. There was a $1,215 \%$ increase (95\% CI 1,032 to $1,396, p<0.001)$ in the proportion of salbutamol delivered by MDI following January 2008 compared to prior to that date.
The numbers of patients presenting with wheeze over the study period increased significantly from an average of 37.2 per week before the intervention to an average of 42.9 per week after January 2008 ( $p=$ $0.004)$. The severity of presenting patients increased over the study period from $62 \%$ of patients triaged as PaedCTAS 1, 2, or 3 preintervention to $71 \%$ postintervention $(p<0.001)$. Hospital admission rates for wheezy patients dropped approximately 32\% compared to preintervention levels, from $22 \%$ to $15 \%$, an absolute drop of $7.25 \%$ (95\% CI -8.31 to $-6.19, p<0.001)$. To control for the influence of possible pre-existing trends, all three of these secondary measures were included in a segmented regression model. The resulting comparison of the intervention and nonintervention segments of the model indicated that there was a difference in mean MDI asthma care map equivalents of 8.40 (95\% CI 7.14 to 9.65 ). This 


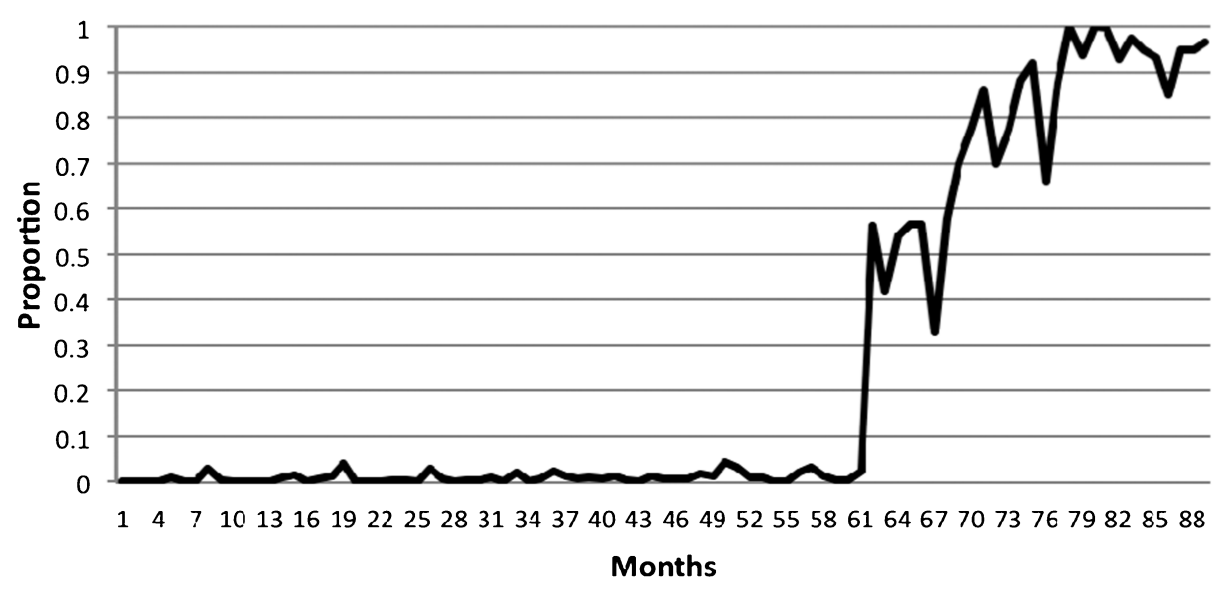

Figure 2. Proportion of asthma care map equivalents represented by salbutamol metered-dose inhalers delivered to the pediatric emergency department from January 1, 2003, to May 31, 2010. represents a change of $966.39 \%$ (95\% CI 822.08 to $1,110.71, p<0.0001)$ related to the study intervention.

\section{DISCUSSION}

Clinical practice interventions to promote MDIs with holding chambers in PEDs have met with varying success. ${ }^{24-27}$ Hendeles and colleagues report a hospital-wide intervention based on respiratory technicians' automatic substitution of MDIs with holding chambers for nebulization orders. ${ }^{24}$ The intervention was largely unsuccessful in the PED, except in situations where patients waiting in the hall did not have access to forced air. Lack of a PED champion may have been a factor. Multifaceted interventions from nebulization to MDIs in pediatric care achieved a $94 \%$ and a $95.5 \%$ conversion in two studies. ${ }^{25,26}$ In contrast, an intervention that employed an outside consultant rather than relying on a local champion changed MDI use from 9 to $26 \% .^{27}$

Health service practice change remains a complex process, and gaps persist in our understanding of what leads to successful interventions. Rogers' classic diffusion of innovation model, described as one of the most influential frameworks for understanding clinical practice interventions, states that the interaction between the innovation, the adopter, and the environment influences the success of the intervention. ${ }^{28}$ Characteristics that may affect an intervention's success include the perceived relative advantage offered; the compatibility with the adopter; the complexity of the change; the trialability; and the observability..$^{28,29}$

Behaviour change may be predicted by the readiness of the adopter and facilitated by a preimplementation process of barrier identification. ${ }^{28}$ The local barrier analysis was a major factor in preparing the PED for change, providing an outlet for concerns and prompting discussions on meeting the challenges of the identified barriers. ${ }^{20}$ The culture of both the PED and the institution itself facilitates research and innovation, contributing to adopter readiness. In our view, the conversations, educational sessions, and negotiations that occurred over a 2-year period prepared the staff in various departments for the successful change in clinical practice.

Ganz and colleagues identified key attributes that encourage health care professionals to engage in behavioural change: simplicity, trialability, observability, reinvention, and risk minimization. ${ }^{29}$ Ganz and colleagues also noted that innovations that place the responsibility for quality of care in the hands of frontline staff and involve a collective team responsibility are keys to success. Our intervention met with each of these attributes. Although the intervention process was complex, at the patient level, the change was straightforward, involving the substitution of one familiar inhalation method with another (simplicity). Educational reinforcement was minimal, and no new staffing resources were required. The tailored asthma care map was introduced as a trial document, and interprofessional staff input resulted in amendments (trialability). The efficacy of the therapy, in conjunction with notable decreases in patient distress and ambient noise from the drug delivery system, meant that front-line workers immediately saw benefits (observability). Initially introduced for moderate illness in toddlers and older children, the scope of the intervention quickly spread to younger and sicker children. The use of the asthma care map is voluntary in this setting (reinvention). As well, it allows for adaptation by individual clinicians (e.g., with regard to 
steroid dosing), specific patient requirements, or, rarely, parental expectations. The map allows the clinician to choose the method of salbutamol delivery (MDI versus nebulization). Finally, the volume of published evidence and synthesized knowledge related to this delivery change meant that there was an extremely low clinical risk (risk minimization).

Furthermore, by design, the intervention engaged front-line staff. This intervention encourages "reallife" teaching of MDI and holding chamber technique to patients and families and presents ample opportunity for reinforcement and correction. Optimal outcomes can be achieved with this administration method only when proper technique is used. ${ }^{10}$

One of the perceived barriers identified in the previous study was increased cost. ${ }^{20}$ The disinfection and reuse of the holding chambers up to six times and the use of a patient's own holding chambers and MDIs have both been adopted to help contain cost. Nursing staff are often able to target the retirement of the holding chambers (on their fifth or sixth use) to patients in financial need.

This intervention has resulted in a shift in clinical practice. In 2001, Powell and colleagues lamented the difficulty of reversing "nebuliser culture," noting that they had considered "it important to change the practice(s) of the major pediatric teaching hospital(s) which [were] perceived as the community leader(s) in child health." ${ }^{35}$ Our PED is involved with more than 100 medical students and postgraduate trainees each year. Diffusion of this intervention through their education and experience will be a significant secondary benefit.

\section{STRENGTHS AND LIMITATIONS}

This study used an interrupted time series design, the strongest quasiexperimental approach for determining the longitudinal impact of an intervention. ${ }^{29}$ Certain limitations are inherent. Linearity is assumed by the analytical model; however, the effect may not follow a linear progression. ${ }^{31}$

The components of the intervention were identified retrospectively, although departmental documents helped identify key dates.

Patient data obtained from the hospital's decision support unit consisted of aggregate data, so individuallevel covariates may confound results. ${ }^{31} \mathrm{We}$ did not have access to individual patient metrics (age, weight), which would have allowed assessment of individual dosing data.

The length of our data (90 months) reduced the effect of seasonal variations in asthma and the H1N1 pandemic on our evaluation.

In December 2008 and January 2009, the PED made a public service announcement broadcast requesting that parents bring in their children's holding chambers when seeking treatment. Patients who revisit the PED were also asked to bring in their MDIs and holding chambers. Nursing staff indicate that in addition to holding chambers, patients' own MDIs may also be used in the PED, offering both potential benefits and risks. ${ }^{32} \mathrm{We}$ were unable to document the extent of this practice; however, the effect on our analysis of personal inhaler and holding chamber use would have acted to blunt the impact of the intervention.

We were unable to examine other factors that may have affected our results, such as industry marketing campaigns, changes in patient's eligibility for private or public drug insurance, changes in staffing, and external publications such as the Canadian pediatric asthma consensus guidelines published in 2005, which encouraged adoption of MDIs. ${ }^{18}$ However, dissemination of guidelines has been shown to be of limited effect in inducing practice change. ${ }^{33}$

The contribution of other unknown or unmeasured factors at the patient, provider, hospital, or health system level is particularly relevant when considering the documented decrease in admission rates for wheezy patients seen postintervention. Given our study design, it was impossible to determine the degree to which the change in delivery of salbutamol from nebulization to MDI contributed to the change in admission rate. Other shifts in clinical practice as a result of the asthma care map included earlier initiation of salbutamol and corticosteroid. Early initiation of salbutamol and the routine and early administration of oral corticosteroids for acute pediatric asthma have been shown to reduce admission rates. ${ }^{34,35}$

Further research is needed to evaluate economic impact, particularly in light of the potential effect on admission rates. ${ }^{14}$

\section{CONCLUSION}

We observed a large practice change in salbutamol inhalation delivery in our PED following an evidence- 
based clinical practice intervention. Over a very short interval, practice changed from administering salbutamol almost always by nebulization to nearly complete use of MDIs with holding chambers. By employing leading practices in health service change management, specifically adapted to the context of the practice environment, significant improvement was achieved. Quantitative findings and documentation of the intervention components may be used to inform the process of introducing a well-considered, locally developed intervention into other busy acute care settings.

Acknowledgements: We acknowledge the assistance of Ethel Langille Ingram, Jeanne Smith, Janet Curran, and Brett Taylor and the staff members of the IWK PED and IWK Decision Support Unit.

Competing interests: Funding was provided through the Drug Use Management and Policy Research Residency Program, a component of the Health Services Research Chair held by Dr. Ingrid Sketris, Dalhousie University, which was funded by the Canadian Health Services Research Foundation/Canadian Institutes of Health Research and cosponsored by the Nova Scotia Health Research Foundation.

\section{REFERENCES}

1. Amirav I, Newhouse MT. Metered-dose inhaler accessory devices in acute asthma - efficacy and comparison with nebulizers: A literature review. Arch Pediatr Adolesc Med 1997; 151:876-82, doi:10.1001/archpedi.1997.02170460014003.

2. Benito-Fernández J, González-Balenciaga M, CapapéZache S, et al. Salbutamol via metered-dose inhaler with spacer versus nebulization for acute treatment of pediatric asthma in the emergency department. Pediatr Emerg Care 2004;20:656-9, doi:10.1097/01.pec.0000142948.73512.81.

3. Cates CJ, Crilly JA, Rowe BH. Holding chambers (spacers) versus nebulisers for beta-agonist treatment of acute asthma. Cochrane Database Syst Rev 2006;(2)CD000052, DOI:10. 1002/14651858.CD000052.pub2.

4. Chou KJ, Cunningham SJ, Crain EF. Metered-dose inhalers with spacers vs nebulizers for pediatric asthma. Arch Pediatr Adolesc Med 1995;149:201-5, doi:10.1001/archpedi.1995. 02170140083015.

5. Cunningham SJ, Crain EF. Reduction of morbidity in asthmatic children given a spacer device. Chest 1994;106:7537, doi:10.1378/chest.106.3.753.

6. Dewar AL, Stewart A, Cogswell JJ, et al. A randomised controlled trial to assess the relative benefits of large volume spacers and nebulisers to treat acute asthma in hospital. Arch Dis Child 1999;80:421-3, doi:10.1136/adc.80.5.421.

7. Leversha AM, Campanella SG, Aickin RP, et al. Costs and effectiveness of spacer versus nebulizer in young children with moderate and severe acute asthma. F Pediatr 2000;136: 497-502, doi:10.1016/S0022-3476(00)90013-1.

8. Rubilar L, Castro-Rodriguez JA, Girardi G. Randomized trial of salbutamol via metered-dose inhaler with spacer versus nebulizer for acute wheezing in children less than 2 years of age. Pediatr Pulmonol 2000;29:264-9, doi:10.1002/ (SICI) 1099-0496(200004)29:4<264::AID-PPUL5> 3.0.CO; $\underline{2-\mathrm{S}}$.

9. Schuh S, Johnson DW, Stephens D, et al. Comparison of albuterol delivered by a metered dose inhaler with spacer versus a nebulizer in children with mild acute asthma. $\mathcal{F}$ Pediatr 1999;135:22-7, doi:10.1016/S0022-3476(99)70322-7.

10. Dolovich MB, Ahrens RC, Anderson P, et al. Device selection and outcomes of aerosol therapy: Evidence-based guidelines: American College of Chest Physicians/American College of Asthma, Allergy, and Immunology. Chest 2005; 127:335-371, doi:10.1378/chest.127.1.335.

11. Scott SD, Osmond MH, O'Leary KA, et al. Barriers and supports to implementation of MDI/spacer use in nine Canadian pediatric emergency departments: A qualitative study. Implement Sci 2009;4:65, doi:10.1186/1748-5908-465 .

12. Mason N, Roberts N, Yard N, et al. Nebulisers or spacers for the administration of bronchodilators to those with asthma attending emergency departments? Respir Med 2008; 102:993-8, doi:10.1016/j.rmed.2008.02.009.

13. Babl FE, Sheriff N, Borland M, et al. Paediatric acute asthma management in Australia and New Zealand: Practice patterns in the context of clinical practice guidelines. Arch Dis Child 2008;93:307-12.

14. Clark NM, Houle C, Partridge MR, et al. The puzzle of continued use of nebulized therapy by those with asthma. Chron Respir Dis 2010;7:3-7, doi:10.1177/ $\underline{1479972309357496 .}$

15. Osmond MH, Gazarian M, Henry RL, et al. Barriers to metered-dose inhaler/spacer use in Canadian pediatric emergency departments: A national survey. Acad Emerg Med 2007;14:1106-13.

16. Rallo M, Bertone A, Bignamini E. Guala A. Lack of use of MDI device in acute asthma: An Italian survey. Pediatr Pulmonol 2009;44:1244-5, doi:10.1002/ppul.21118.

17. Global Initiative for Asthma. Global strategy for the diagnosis and management of asthma in children 5 years and younger. 2009. Available at: http://www.ginasthma.org (accessed October 25, 2010).

18. Becker A, Bérubé D, Chad Z, et al. Canadian Network For Asthma Care; Canadian Thoracic Society. Canadian Pediatric Asthma Consensus guidelines, 2003 (updated to December 2004): Introduction. CMAJ 2005;173(6 Suppl):S12-14.

19. National Asthma EducationPrevention Program. Expert panel report 3 (EPR-3): Guidelines for the diagnosis and management of asthma-summary report 2007. F Allergy Clin Immunol 2007;120(5 Suppl):S94-138.

20. Hurley KF, Sargeant J, Duffy J, et al. Perceptual reasons for resistance to change in the emergency department use of holding chambers for children with asthma. Ann Emerg Med 2008;51:70-7, doi:10.1016/j.annemergmed.2007.04.008.

21. IWK Health Centre. About Us. 2009. Available at: http:// www.iwk.nshealth.ca. (accessed October 25, 2010).

22. Canadian Institutes of Health Information. Database background and general data limitations documentation. National Ambulatory Care Reporting System. 2008-2009. Executive Summary. Ottawa: CIHI; 2009. Available at: http://www. 
cihi.ca/CIHI-ext-portal/pdf/internet/nacrs_exec_summ_2008_ 2009_EN (accessed November 6, 2012).

23. World Health Organization. International statistical classification of diseases and related health problems: tenth revision. 2nd ed. 2004. Available at: http://www.who.int/classifications/icd/en/ (accessed October 25, 2010).

24. Hendeles L, Hatton RC, Coons TJ, et al. Automatic replacement of albuterol nebulizer therapy by metered-dose inhaler and valved holding chamber. Am $\mathcal{F}$ Health Syst Pharm 2005;62:1053-61.

25. Gazarian M, Henry RL, Wales SR, et al. Evaluating the effectiveness of evidence-based guidelines for the use of spacer devices in children with acute asthma. Med 7 Aust 2001;174:394-7.

26. Powell CV, Maskell GR, Marks MK, et al. Successful implementation of spacer treatment guideline for acute asthma. Arch Dis Child 2001;84:142-6, doi:10.1136/adc.84.2.142.

27. Gildenguys J, Lee M, Isbister GK. Does implementation of a paediatric asthma clinical practice guideline worksheet change clinical practice. Int 7 Emerg Med 2009;2:33-39, doi:10.1007/s12245-008-0063-x.

28. Rogers EM. Diffusion of innovations. 4th ed. New York: The Free Press; 1995.

29. Ganz DA, Yano EM, Saliba D, Shekelle PG. Design of a continuous quality improvement program to prevent falls among community-dwelling older adults in an integrated healthcare system. BMC Health Serv Res 2009;9:206, doi: 10.1186/1472-6963-9-206.

30. England E. How interrupted time series analysis can evaluate guideline implementation. Pharm 7 2005;275:344-347.

31. Wagner AK, Soumerai SB, Zhang F, Ross-Degnan D. Segmented regression analysis of interrupted time series studies in medication use research. 7 Clin Pharm Ther 2002; 27:299-309, doi:10.1046/j.1365-2710.2002.00430.x.

32. Lummis H, Sketris I, Veldhuyzen van Zanten S. Systematic review of the use of patients' own medications in acute care institutions. 7 Clin Pharm Ther 2006;31:541-63, doi:10.1111/ j.1365-2710.2006.00773.x.

33. Sketris IS, Langille Ingram EM, Lummis HL. Strategic opportunities for effective optimal prescribing and medication management. Can 7 Clin Pharmacol 2009;16:e103-25.

34. Rowe BH, Spooner C, Ducharme F, et al. Early emergency department treatment of acute asthma with systemic corticosteroids. Cochrane Database of Systematic Reviews 2001;(1): CD002178. Doi:10.1002/14651858.CD002178.

35. Bhogal SK, McGillvray D, Bourbeau J, et al. Early administration of systemic corticosteroids reduces hospital admission rates for children with moderate and severe asthma exacerbation. Ann Emerg Med 2012;60:84-91. e3. Epub 2012 Mar 10. Doi:10.1016/j.annemergmed.2011.12.027.

36. Bowton D, Goldsmith W, Haponik E. Substitution of metered-dose inhalers for hand-held nebulizers. Success and cost savings in a large acute-care hospital. Chest 1992;101: 305-8, doi:10.1378/chest.101.2.305.

37. Khoo SM, Tan LK, Said N, et al. Metered-dose inhaler with spacer instead of nebulizer during the outbreak of severe acute respiratory syndrome in Singapore. Respir Care 2009;54:855-60, doi:10.4187/0020132097938 00411 .

38. Rodriguez-Martinez CE, Sossa M, Lozano JM. Commercial versus home-made spacers in delivering bronchodilator therapy for acute therapy in children. Cochrane Database Syst Rev 2008;(2):CD005536. 